On the other hand, the threshold measurement in the present experiment does indicate absolute sensitivity. And since the data show that absolute sensitivity increases (threshold energy decreases) with caffeine administration, this fact lends support to the speculation that retinal "on" fibers become more sensitive with caffeine.

Why then was enhancement also not affected in the present threshold experiment, as it was in Kleman's brightness match experiment? One explanation may be in the probable constancy of "on" fiber activity for a threshold response. That is, regardless of the amount of stimulus or whether or not caffeine has been administered, we might assume that the minimal amount of physiological activity necessary to produce the threshold response remains constant, since the threshold sensation by definition and by instruction is presumed constant. For threshold measurement in the present experiment, therefore, although the "on" fibers might become more sensitive, the amount of "on" activity remains the same regardless of the administration of caffeine. If "on" activity, therefore, is in fact constant, we would predict no change in enhancement. (In Kleman's experiment, "on" activity might be assumed to have increased with caffeine administration although, as pointed out above, his binocular match procedure did not provide a measure of such a change.)

One further consideration involves the role of the "off" fiber in the retina. Diamond (1960) suggests that both singleand multiple-field enhancement can be explained in terms of an inhibition of "off" retinal activity resulting in a disinhibition (see Hartline \& Ratliff, 1959) of test brightness. In the single-field situation, as the test area increases, its light turns off more and more "off" fibers that were initially depressing the test-field's "on" activity (see Granit, 1955, for a discussion of "on-off" antagonism). For Kleman's multiple-field enhancement, the introduction of a low luminance surround theoretically eliminates "off" activity in the area surrounding the test field and again the disinhibited test brightness increases

Since enhancement did not change in the present experiment, then, according to the above theoretical account, "off" fiber activity probably was not affected by caffeine administration, even though "on" fiber sensitivity was. In this connection, it is interesting to note that a number of investigators suggest differences between "off" and "on" retinal systems (MacNichols \& Love, 1960; Ratliff, 1965), whereas others suggest that the "off" response might be a "rebound" (Florey, 1961) or a "net summation" (Kennedy, 1963) of the "on" responses. The results of the present study, interpreted in the light of Diamond's theoretical account (1960), would tend to support the idea of some functional difference between "on" and "off" systems and that this difference, whatever it might be, shows up as a differential response to caffeine, the "on" system being made more sensitive to stimuli and the "off" system not significantly affected.

\section{REFERENCES}

DIAMOND, A. L. Foveal simultaneous contrast as a function of inducing-field area. Journal of Experimental Psychology, 1955, 50, 14-152.

DIAMOND, A. L. A theory of depression and enhancement in the brightness response. Psychological Review, 1960, 67, 168-199.

DIAMOND, A. L. Brightness of a field as a function of its area. Journal of the Optical Society of America, 1962, 52, 700-706.

DITCHBURN, R. W., \& POWER-STEELE, E. J. Effect of caffeine and bromide on dark adaptation. Nature, London, 1941, 1, 745-746.

FLOREY, E. Nervous inhibition: Proceedings of the Second Friday Harbor Symposium. New York: Pargamon Press, 1961. Pp. 318-325.
GRAHAM, C. H., BROWN, R. H., \& MOTE, F. $A$. The relation of size of stimulus and intensity in the human eye: I. Intensity thresholds for white light. Journal of Experimental Psychology, 1939, 24, 555-573.

GRANIT, R. Receptors and sensory perception. New Haven: Yale University Press, 1955.

HARTLINE, H. K. The effects of spatial summation in the retina of the excitation of the fibers of the optic nerve. American Journal of Physiology, 1940, 130, 700-711.

HARTLINE, H. K., \& RATLIFF, F. Inhibitory interaction of receptor units in the eye of Limulus. Journal of General Physiology, 1957, 40, 357-376.

HEINEMANN, E. G. Simultaneous brightness induction as a function of inducing and test-field luminances. Journal of Experimental Psychology, 1955, 50, 89-96.

KENNEDY, D. Inhibition in visual systems. Scientific American, July 1963, 2-8.

KLEMAN, J. P., DIAMOND, A. L., \& SMITH, E. Effects of caffeine on enhancement in foveal simultaneous contrast. Journal of Experimental Psychology, 1961, 61, 18-2.

MacNICHOL, E. F., JR., \& LOVE, W. E. Electrical responses of the retinal nerve and optic ganglia of the spine. Science, 1960, 132, 737-738.

RATLIFF, F. Mach bands: Quantitative studies on neural networks in the retina. San Francisco: Holden-Day, 1965.

STEVENS, S. S. Handbook of experimental psychology. New York: Wiley, 1951.

\title{
Short-term retention and similarity of word length
}

\author{
HAROLD L. HAWKINS and R. HAL SHIGLEY \\ University of South Florida, Tampa, Fla. 33620
}

The short-term retention of lists containing word quadruples identical in length was measured by the Peterson method. Nine blocks of three lists were presented. The successively presented lists comprising a block contained words identical in length, 3,6 , or 9 letters, while word length varied across blocks. Overall retention declined with increasing word length. Retention also declined with increasing number of successive lists containing words of a common length and increased when immediately preceding lists contained words of different length, indicating that proactive interference varies as a function of the similarity in length of recently stored items.

Keppel \& Underwood (1962) have demonstrated that a major portion of the forgetting observed in short-term retention under conditions first described by Peterson \& Peterson (1959) is attributable to proactive interference (PI). Subsequently, several investigators have shown that PI can be effectively manipulated in the Peterson situation by varying the similarity relationship between adjacent lists (Wickens, Born, \& Allen, 1963; Loess, 1968; Hawkins, Martini, \& Sayre, 1969). In the Wickens et al study, Ss were initially tested on a series of lists consisting exclusively of either consonant or digit trigrams. A second series contained trigrams of either the same class or of the alternate class. When trigram class remained constant across series, marked PI was observed in as few as three trials. However, when trigram class altered, PI was not evident, indicating a "release from PI" with changing material. Comparable results were reported by Loess (1968) in a study varying the taxonomic category of successive word triads and by Hawkins et al (1969) in a study varying interlist acoustic similarity. 
Table 1

Mean Ordered Recall Errors at Each List Position and Word Length

\begin{tabular}{|c|c|c|c|c|}
\hline \multirow{2}{*}{$\begin{array}{l}\text { Nord } \\
\text { Length } \\
\text { (Letters) }\end{array}$} & \multicolumn{2}{|c|}{ List } & \multicolumn{2}{|c|}{ Within Blocks } \\
\hline & 1 & 2 & 3 & $\overline{\mathrm{X}}$ \\
\hline 3 & 4.36 & 4.89 & 5.14 & 4.80 \\
\hline 6 & 5.64 & 6.36 & 6.74 & 6.25 \\
\hline 9 & 5.58 & 6.38 & 6.78 & 6.24 \\
\hline$\overline{\mathrm{X}}$ & 5.19 & 5.88 & 6.22 & 5.76 \\
\hline
\end{tabular}

The present experiment further investigates the effects of interlist class relations as a determinant of $P I$ by varying word length across successively presented lists in a short-term retention task. Each list contained four familiar English words of a single length, 3,6, or 9 letters. Word length remained constant within blocks of three successive lists and varied across blocks.

\section{SUBJECTS}

The Ss were 36 introductory psychology students, 21 men and 15 women, who received course credit for their services. None had previously participated in an experiment on short-term retention.

STIMULUS MATERIALS

Stimuli consisted of 36 highly familiar words of each of three lengths, 3,6 , or 9 letters. Half the words of each length were rated as $\mathrm{A}$ and the remainder as $\mathrm{AA}$ according to the Thorndike-Lorge (1944) $\mathrm{G}$ count. The set of words of each length were partitioned into nine four-word lists. Each S was tested on all 27 resulting lists. PROCEDURE

The Ss were tested individually during a single session lasting about $30 \mathrm{~min}$. The four words constituting each list were typed in upper-case letters and presented separately on a Lafayette memory drum at a 1-sec rate. Each list was followed immediately on the drum by a three-digit number. The $S$ was instructed to recite the number aloud and orally subtract by threes for $10 \mathrm{sec}$. At the completion of this interval, E uttered a "recall" signal and allotted $20 \mathrm{sec}$ for the oral recall of the four words in their order of appearance. Five seconds following completion of recall, $E$ initiated presentation of the succeeding list. To ensure that $\mathrm{Ss}$ understood instructions and could satisfactorily perform the interpolated subtraction task, a training trial containing a two-letter word list was provided at the beginning of the experimental session.

The nine lists containing words of a given length were randomly divided into three blocks of three, and the three lists comprising a block were presented consecutively. The presentation order of blocks within the total 27-list series was separately randomized for each $S$, with the constraint that two blocks representing a given word length could not appear in succession. Two separately randomized assignments of words to lists within lengths were constructed and half the Ss were tested under each assignment.

\section{RESULTS AND DISCUSSION}

Table 1 gives the mean number of ordered recall errors obtained under each of the three within-block list positions ( 1 , $2,3)$ and the three levels of word length $(3$, 6,9 letters). The value appearing in each cell of the table is the average, across Ss, of the total number of errors made on the three lists of words of a given length appearing at a given within-block position. These data were subjected to an analysis of variance with repeated measurements on both list position and word length. List position, $F(2 / 70)=6.08$, and word length, $F(2 / 70)=23.90$, were both significant at the .01 level. Fisher's least-significantdifference (LSD) test, with the criterion of significance at .05, was used to evaluate differences between means. This analysis revealed that errors increased significantly from List Position 1 to Positions 2 and 3, indicating the rapid within-block development of PI, and also increased from Word Length 3 to Lengths 6 and 9.

To achieve a more detailed analysis of the overall error data appearing in Table 1 , the ordered recall errors were partitioned into item errors (importations plus omissions) and order errors. Order error scores were then transformed into proportions representing the ratio of the number of to-be-recalled items recalled in incorrect order to the total number correctly recalled regardless of order. In the analysis of item errors, both list position, $F(2 / 70)=5.34$, and word length, $F(2 / 70)=6.14$, were significant at the .01 level. The LSD test indicated that item errors increased across all three list positions and increased from Word Length 3 to Lengths 6 and 9 . Neither list position nor word length reached significance in the analysis of the transformed order error scores. The results suggest that the within-block PI effect observed in this study is principally due to an increase in competition from prior items that are equal in length to those comprising the current list.

An examination of ordered recall scores across blocks revealed that errors were lower for the first list of each block than for the last list of the preceding block for all eight blocks following the first $(p<.01$, sign test), evidencing a release from PI with changing word length.

The present findings, together with those of Wickens et al (1963), Loess (1968), and Hawkins et al (1969), are generally consistent with the view (Melton, 1963) that the development of PI is dependent upon a selector mechanism limiting retrieval accessibility to items recently stored in memon that are class congruent with those comprising the current list. From this perspective, the variations in PI observed across levels of interlist similarity in the aforementioned studies may be interpreted as a result of experimentally induced fluctuations in the number of recently stored items that, on the basis of their generic similarity to current items, pass through the accessibility filter to compete at recall.

Murdock (1961) has found no differences in forgetting between consonant and monosyllabic word triads in the Peterson situation, suggesting that short-term retention is relatively insensitive to item length when items are familiar integral units such as words. The increase in errors from 3- to 6- and 9-letter word lists found in the present study indicates a limitation to the generality of the Murdock finding. The apparent discrepancy between these two sets of results may be related to the fact that acoustic complexity (defined as the number of syllables per item) increased with word length in the present experiment, i.e.. 3-letter words were uniformly monosyllabic, 6-1etter words were uniformly bisyllabic, and 9-letter words averaged 2.95 syllables. Accordingly, the present results raise the possibility that monosyllabic verbal units or "chunks" (Miller, 1956) are encoded and/or retrieved in short-term retention more efficiently than are polysyllabic units. REFERENCES

HAWKINS, H. L, MARTINI, J., \& SAYRE, L. Proactive interference in short-term recognition: Trace integration and/or competition? Lnpublished manuscript. University of South Florida, 1969.

KEPPEL, G., \& UNDERWOOD, B. J. Proactive inhibition in short-term retention of individual items. Journal of Verbal Learning \& Verbal Behavior, 1962, 1, 310-329.

LOESS, H. Short-term memory and item similarity. Journal of Verbal Learning \& Verbal Behavior, 1968, 7, 87-92.

MELTON, A. W. Implications of short-term memory for a general theory of memory. Journal of Verbal Leaming \& Verbal Behavior. 1963. 2. 1-21.

MILLER, G. A. The magical number seven, plus or minus two: Some limits on our capacity for processing information. Psychological Review, 1956, 63. 81-97.

MURDOCK. B. B., JR. The retention of individual items. Journal of Experimental Psychology, 1961, 62, 618-625.

PETERSON, L. R.. \& PETERSON, M. J. Short-term retention of individual verbal items. Journal of Experimental Psychology, 1959, 58, 193-198.

THORNDIKE, E. L., \& LORGE, I. The teacher's word book of 30,000 words New York: Bureau of Publications, Teachers College. Columbia Liniversity, 1944.

WICKENS. D. D. BORN, D. G., \& ALLEN, C. K. Proactive inhibition and item similarity in short-term memory. Journal of Verbal Learning \& Verbal Behavior, 1963, 2, 440-445. 